\title{
Empowerment and ownership in effective internationalisation of the higher education curriculum
}

\author{
Sandra H. Kirk ${ }^{1}$ - Clare Newstead ${ }^{2} \cdot$ Rose Gann $^{3}$ • \\ Cheryl Rounsaville ${ }^{4}$
}

Published online: 6 March 2018

(C) The Author(s) 2018. This article is an open access publication

\begin{abstract}
Internationalising the curriculum (IOC) in order to produce graduates with global citizenship skills is a common strategic goal in modern higher education. The extent to which this is achieved and the level of understanding amongst staff and students of what IOC involves and the benefits it imparts are varied. In this study, activities and attitudes across 15 subject disciplines delivered in a modern UK university were surveyed through an analysis of official course documentation, and semi-structured interviews with a range of academic staff. The outcomes are discussed in relation to the level of understanding and ownership that staff have of IOC. Through the modification of a process control model Barnett (European Journal of Education, 29(2), 165-179, 1994), suggestions are made as to how to move this top-down strategic imperative forward through empowerment of the academic staff involved in course delivery.
\end{abstract}

Keywords Empowerment· Ownership - Internationalisation

\section{Introduction}

According to the International Association of Universities 4th Global Survey on internationalisation in higher education, $75 \%$ of over 1300 institutions in 131 countries either

Sandra H. Kirk

Sandra.kirk@ntu.ac.uk

School of Science \& Technology, Nottingham Trent University, Clifton Lane, Nottingham NG11 $8 \mathrm{NS}$, UK

2 College of Science \& Technology, Nottingham Trent University, Clifton Lane, Nottingham NG11 $8 \mathrm{NS}, \mathrm{UK}$

3 School of Social Sciences, Nottingham Trent University, 50 Shakespeare St, Nottingham NG1 4FQ, UK

4 NTU Global, Nottingham Trent University, 50 Shakespeare St, Nottingham NG1 4FQ, UK 
had a policy for internationalisation, or were in the process of preparing one (Egron-Polak and Hudson 2014). While many view student recruitment as important, institutions ranked increasing the international awareness of students as the top driver for internationalisation. Despite this widespread commitment to internationalisation at the institutional level, there remain clear challenges to embedding key elements of internationalisation into organisational cultures. Over 20 years ago, Knight (1994) described the academic activities and services, and organisational factors needed for the development and success of an international culture in a Canadian institution. These included raising awareness amongst all relevant stakeholders, ensuring staff commitment, clear planning, effective operationalisation, review, and reinforcement. That staff buy-in is fundamental to the success of internationalisation and, in particular, in ensuring that students receive maximum benefit from this strategic imperative is now widely accepted within the literature, yet it remains a key challenge (Clifford and Montgomery 2015; Dewey and Duff 2009; Leask and Beelen 2009; Friesen 2012; Leask 2015).

In Knight's view, a critical mass of $15 \%$ of staff fully engaged is necessary for success, but it is not uncommon to hear international office staff describe responses to internationalisation in their institutions as at best uneven, with pockets of excellence often disconnected from overall institutional strategies. Disciplinary differences shape this picture, with evidence of excellence being found in disciplines such as languages and business studies, while staff in science subjects often appear resistant and yet-to-be convinced of the benefits of internationalisation (Clifford 2009; Leask and Bridge 2013; Newstead et al. 2015; Sawir 2011). Yet, across all disciplines, the ways in which internationalisation strategies are presented to staff appear to matter. Research over the last 15 years consistently points to a lack of communication and discussion between institutions and their staff, weak levels of support for the internationalisation agenda, its goals and underlying values, and persistent gaps between strategy claims and practices in the classroom (Bond et al. 2003; Dewey and Duff 2009). Knight (1994) suggests that while "[a] $\mathrm{n}$ internationalization plan tailored to build on the specific interests, characteristics and objectives of the College or University has a better chance of success than a general purpose strategy", (p. 13) institutions often fail properly to articulate their ambitions to specific contexts and existing organisational cultures. Bond et al. (2003) suggested that in addition to a lack of discussion and debate within institutions, there are often issues of inadequate institutional support, work overload, and lack of respect for disciplinary specifics. Dewey and Duff (2009) further highlight that there is frequently a lack of recognition of and reward for the efforts involved in changing cultures. This was still being reported as a problem in the sector by Florenthal and Tolstikov-Mast, as recently as 2012.

Barnett (1994) suggests, in his work on quality assurance, that the implementation of new initiatives in universities is frequently resisted by staff as a bureaucratic imposition when there are low levels of academic autonomy. Like quality assurance, internationalisation strategies can often appear as top-down mechanisms that serve the economic interests of universities in a changing global context but further regulate and constrain academic freedom in relation to curriculum design and delivery. His work alerts us to issues arising when changes become detached from the communities delivering them. In this paper, we draw on data obtained in a 2014/2015 study of curriculum internationalisation at Nottingham Trent University (NTU), a large modern, urban UK University, to further explore and analyse staff understanding and engagement with internationalisation. While recognising that internationalisation is multidimensional, our analysis focused on internationalisation of the curriculum (IOC), an area that many institutions now see as critical to the development of globally engaged graduates and where active academic engagement is essential. This study draws upon Barnett's (1994) work 
on approaches to embedding assurance practices in higher education to bring into relief issues regarding control and ownership of internationalising the curriculum.

In the next section, some of the strategic drivers for IOC at an institutional level are introduced. The extent to which these drivers are reflected in curricula at NTU, through an examination of course documentation, is considered across 15 subject disciplines ${ }^{1}$ : Art and Design; Biosciences; Communications, Media, Film and Cultural Studies; Computing; Construction, Property and Surveying; Early Childhood Studies; Earth Science, Environmental Science and Environmental Studies; Forensic Science; General Business and Management; History; Languages and Related Studies; Law; Physics and Astronomy; Politics and International Relations; and Psychology. This document analysis, along with 24 semi-structured interviews, provides insights into the extent to which academic staff have articulated approaches to achieving new strategic ambitions around internationalisation into their course materials. In the sections that follow, these findings are explored, highlighting points of disconnect between institutional drivers and implementation strategies and staff understanding of the implications of change for their own teaching and learning.

\section{Institutional drivers and implementation strategies}

Narrow interpretations of internationalisation over the last two decades have linked it primarily to the marketisation of higher education and the recruitment of international students (Clifford 2009; Sawir 2013). It is in this context that institutions initially pursued curriculum internationalisation as a means to provide support for international students and ensure their success through induction into western higher educational methods and practices (Clifford 2009, 2011; Sawir 2011, 2013). More recently, institutional understandings of IOC have shifted - at least in the terms by which strategies are articulated - to include focus on internationalisation for the whole student body (Bell 2004; Clifford 2009; Sawir 2011, 2013). This has been associated with a drive to increase outbound mobility (Crowther et al. 2000; Clifford 2011), and to ensure opportunities are available for students to develop globally relevant skills. These broader conceptions arise from the belief that universities are obligated to make all of their students aware of their role as global citizens in an increasingly internationalised, multicultural world and to prepare them for success in the global labour market (Clifford 2009, 2011; Sanderson 2011; Hayden 2013; Harrison 2015; Leask 2015). While these new initiatives are still driven by market demands, there is a greater breadth to current understandings of IOC, and with this come significant implications for the practices of learning and teaching, curriculum design, and delivery. Both a focus on developing an inclusive pedagogy for international students and a range of internationalisation at home and off-campus activities are issues that have to be addressed locally by academic teams.

The NTU institutional Strategic Plan for 2010-2015 (the time period in which this research was conducted) highlighted internationalisation as integral to the work of the University and focused on three specific strands of work in this area: international student recruitment, international research collaborations, and IOC. IOC was linked to inspiring and enabling student ambitions, and ensuring acquisition of relevant globally transferable skills. In part, this was to be achieved through increased outbound mobility, but it was also recognised that international students provided "a valuable resource in

\footnotetext{
${ }^{1}$ As defined by UK QAA subject benchmark statements: available at qaa.ac.uk
} 
helping home students to prepare for success in an international context," as did the international experiences and work of staff.

"Global Citizenship" was listed in the Plan as a core graduate attribute, and was described as encompassing the following traits:

- International awareness and openness to the world, based on appreciation of social and cultural diversity, respect for human rights, and dignity

- Understanding and appreciation of social, economic, or environmental sustainability issues

- Leadership capacity, including a willingness to engage in constructive public discourse, and to accept social and civic responsibility

This rich and detailed understanding of global citizenship challenged previous definitions that narrowly focused on skills acquisition and employability, and pushed the University to consider a comprehensive definition of what was to be achieved through IOC, including values and attitudes. Unfortunately, this was not reinforced by integration of the term elsewhere in the Plan, potentially diluting its importance.

In 2012, a more detailed Internationalisation $\operatorname{Plan}^{2}$ was issued as a supplement to the institutional strategic plan, and this set out the University's medium-term goals with regards to internationalisation. No expanded definition of global citizenship was provided, though a particular understanding was reaffirmed through reference to "highly employable global citizens" and emphasis on the importance of enhancing the learning experience and employability of NTU students. The plan clearly identified international learning as important, suggesting that in order to "succeed in a globalised labour market, graduates must be capable of working across national borders alongside colleagues from a range of cultural, ethnic, linguistic and religious backgrounds". The Plan, however, did not refer to the larger benefits to society or the potentially transformative experience for students of becoming global citizens as described in the Strategic Plan. It included ambitions regarding student mobility, partnership, and internationalisation of the faculty but stopped short at providing further reference to the learning outcomes of IOC or guidance to staff on how to implement curriculum changes to foster global citizenship.

\section{Documentary evidence of operational implementation of strategy}

During the term of the Strategic Plan, course teams were required to illustrate how the attribute of global citizenship was embedded and achieved through course delivery during validation events and routine course review processes, and it was expected that this would be reflected in course documentation. Documentation thus provides a valuable resource through which to explore how strategic ambitions were translated by staff into teaching and learning practice and, in turn, how these were communicated to students and across course teams. Documents from 155 courses were analysed to identify evidence of and/or reference to activities and approaches associated with IOC. A list of relevant activities and approaches was developed based on the language and ambitions set out in the university's strategic documents and the UK Higher Education Academy's Framework for Internationalising Higher Education (2014).

${ }^{2}$ NTU Internationalisation Plan 2012-2015: https://www4.ntu.ac.uk/about_ntu/global_ university/internationalisation_strategy/146831.pdf 
While the emphasis of this project was on how strategic ambitions translated into the design and delivery of courses in one institution, the breadth of the Framework and its embeddedness in current literature and sector-wide practice enabled inclusion in the audit of activities and approaches that were acknowledged as relevant to IOC and may be present in the curriculum but that had not necessarily been flagged formally within the institutional priorities. Two research assistants analysed official NTU documentation - course specifications, validation documents - checking with each other and the authors to ensure consistency of approach. Findings were discussed and conclusions drawn at regular meetings with the authors. While the approach started with presences and absences of information in documents, some interpretation was necessary and undertaken. Much discussion focused around the extent to which each activity was actually evidenced. For example, in some cases, reference was made to certain activities and approaches consistent with IOC, but these were not fully elaborated or appeared as "bolt-ons". These were recorded as "weakly articulated". A summary of the evidence across four key indicators/proxy values is presented in Table 1.

Note that these markers link to the following Global citizenship attributes:

1. International awareness and openness to the world, based on appreciation of social and cultural diversity, respect for human rights and dignity-(1), (2), (3), and (4)

Table 1 Mapping of markers of curriculum internationalisation in course documentation. "Weakly articulated" indicates some reference, but lacking full description

\begin{tabular}{|c|c|c|c|c|}
\hline Subject area & $\begin{array}{l}\text { International } \\
\text { mobility } \\
\text { opportunities } \\
\text { (1) }\end{array}$ & $\begin{array}{l}\text { International } \\
\text { networking } \\
\text { opportunities (2) }\end{array}$ & $\begin{array}{l}\text { Identification of cross- } \\
\text { cultural goals in the } \\
\text { curriculum (3) }\end{array}$ & $\begin{array}{l}\text { Awareness of the } \\
\text { multicultural } \\
\text { backgrounds of } \\
\text { students (4) }\end{array}$ \\
\hline Art and Design & $\begin{array}{l}\text { Yes in some } \\
\text { courses }\end{array}$ & $\begin{array}{l}\text { Yes in some } \\
\text { courses }\end{array}$ & Yes in some courses & Weakly articulated \\
\hline Biosciences & $\begin{array}{l}\text { Yes in some } \\
\text { courses }\end{array}$ & Not evident & Yes in some courses & Not evident \\
\hline $\begin{array}{l}\text { Communications, Media, } \\
\text { Film and Cultural } \\
\text { Studies }\end{array}$ & Yes & Yes & Not evident & Weakly articulated \\
\hline Computing & Not evident & Not evident & Weakly articulated & Weakly articulated \\
\hline $\begin{array}{l}\text { Construction, Property } \\
\text { and Surveying }\end{array}$ & Yes & Yes & Yes & Yes \\
\hline Early Childhood Studies & Yes & Not evident & Yes & Yes \\
\hline $\begin{array}{l}\text { Earth Science, } \\
\text { Environmental Science } \\
\text { and Environmental } \\
\text { Studies }\end{array}$ & Yes & Not evident & Yes & Weakly articulated \\
\hline Forensic Science & Not evident & Not evident & Not evident & Weakly articulated \\
\hline $\begin{array}{l}\text { General Business and } \\
\text { Management }\end{array}$ & Yes & Yes & Yes & Yes \\
\hline History & Yes & Not evident & Yes & Yes \\
\hline $\begin{array}{l}\text { Languages and Related } \\
\text { Studies }\end{array}$ & Yes & Yes & Yes & Not evident \\
\hline Law & Yes & Yes & Yes & Yes \\
\hline Physics and Astronomy & Not evident & Not evident & Not evident & Weakly articulated \\
\hline $\begin{array}{l}\text { Politics and International } \\
\text { Relations }\end{array}$ & Yes & Not evident & Yes & Not evident \\
\hline Psychology & $\begin{array}{l}\text { Yes in some } \\
\text { courses }\end{array}$ & Not evident & Not evident & Yes \\
\hline
\end{tabular}


2. Understanding and appreciation of social, economic, or environmental sustainability issues - (1) and (3)

3. Leadership capacity, including a willingness to engage in constructive public discourse, and to accept social and civic responsibility-(1) and (2)

The picture which emerged from the documentary analysis was complex, with some subject areas giving full information on how internationalisation is being addressed and the opportunities this provides for students, including reference to preparing them to work internationally. This is particularly true of the "soft" subjects, such as Childhood Studies and General Business and Management, although even within these not all areas were necessarily addressed. In contrast, documentation in respect of the "hard" science subjects such as Physics and Computing had little overt reference to internationalisation or issues of cultural awareness.

Table 1 illustrates that the majority of areas overtly offer mobility opportunities to students, and include cross-cultural goals in the curriculum, although these appear not always to be accompanied by fully articulated international networking. This implies that mobility may sometimes be added into courses in a formulaic way, rather than being embedded to enable deep cultural engagement, and/or that staff do not recognise and draw out the full potential of these opportunities. In some cases, particularly in some science disciplines, international sandwich placement opportunities are offered, but these are undifferentiated from UK-based placements and not necessarily mined for their internationalisation potential. In contrast, documentation for Fashion courses within the Art and Design subject area makes clear that international mobility creates opportunities for students to gain first-hand insight into global fashion markets, while also enabling them to establish networks that may facilitate future global employment.

The review showed limited documentary information regarding awareness of the international backgrounds of students. This is significant because a lack of attention to diversity in the classroom does not encourage engagement with broader patterns of difference and connection, elements central to the principles of global citizenship and articulated in the Strategic Plan. This possibly reflects the social, cultural, or disciplinary backgrounds of staff and their lack of/ limited inter-cultural experience and training. As noted by Leask and Beelen (2009), staff need to acquire and use intercultural skills, reflecting on these in the light of the requirements of their discipline and the diversity (or lack thereof) and attitudes of their student cohorts for maximum benefit. This is of importance not only in respect of overseas students, but to the multiculturally diverse home student cohorts, and it is a recommendation of this research that more effort is put into staff development in this area.

While the documentary evidence on internationalisation indicates a gap between institutional expectation/instruction and recording, interviews revealed that an absence of reference to internationalisation in course documentation does not always imply a lack of relevant curricular content and activities. Rather, it suggests some fundamental disjunctures in the ways staff engage with and are engaged by the discourses of internationalisation and University strategic ambition.

\section{Staff interviews: revealing opportunities for internationalisation in courses}

Interviews were designed to explore staff understanding of internationalisation, organisational objectives, and evidence of shared understandings of key terms, such as global citizenship. 
Twenty-four interviews were carried out with a mix of course leaders and School leads for internationalisation (so-called international champions) across the full range of 15 subject areas considered. In contrast to the documentary evidence, interviews revealed that a wide range of approaches to internationalisation and opportunities for cross-cultural interactions are offered across all discipline areas at NTU. In practice, more activities are undertaken and included in courses than are reported, particularly in science subjects. For example, forensic science students have had the opportunity to visit and interact with the police force in Avans, Netherlands, at an operational level. Why this is not included in documentation is unclear. In some cases, it may be a result of staff adopting a technicist approach to the preparation of documentation (Barnett 1994) whereby they fill in what is required for university course approval processes, but do not always do full justice to the richness of the curricula offered. It also reflects some disciplinary differences. For example, courses with more seemingly direct internationalised content, such as Business, Law, Politics, and Geography, appeared much more able to articulate the significance of internationalisation to course aims and learning outcomes.

Conversely, lack of inclusion of international approaches and content into curriculum documentation reflected an understanding of disciplinary contexts where internationalisation is not necessarily seen as an advantage. For example, in one area of Biosciences, there was the perception that future employers saw internationalisation as replacing UK material on the curriculum and, therefore, as disadvantaging students in the UK job market where "The key set of skills, the skills that will really get you jobs in consultancy are being able to identify British things: plants, beetles".

Interviews suggested, however, that what might appear on the surface to be either a technicist approach to writing course documentation or disciplinary differences in the perceived relevance of internationalisation may actually reflect a lack of depth of understanding and/or confidence with the relevant concepts. This was clear with IOC more generally, but more specifically with global citizenship.

\section{Internationalising the curriculum}

When asked what they understood by internationalising the curriculum, a range of staff replies were forthcoming, from those with no/little idea, to some deeply considered responses from those who had thought hard about this in informing their practice. Such variation across an institution in understanding is significant and suggests not only the limits of engagement with institutional strategy but also the existence of multiple and diverse local cultures of internationalisation. Discussion about IOC as a strand of the internationalisation of higher education goes as far back in the literature as the 1990s (van der Wende 1997), and although it is now recognised as an important and growing aspect, there is still no consensus on a definition (Bell 2004; Clifford 2009; Green and Whitsed 2012; Hayden 2013; Harrison 2015), or an identified "best approach" to IOC in practice in all contexts (De Vita and Case 2003; Green and Whitsed 2012; Leask 2013). Bell (2004) offers a possible reason for this, stating “...internationalising the curriculum is a construct, not a clearly defined set of ideal or best practices" (p. 2) while Green and Whitsed (2012) posit that “...IoC is the most difficult to define because it couples two fuzzy, ideologically laden terms: "internationalization" and "curriculum" (p. 3).

The research reported here showed a lack of shared institutional understanding of IOC. Some disciplines extol a comprehensive and relatively well-established definition: for instance, 
interviewees from the Business School identified internationalisation as involving increased opportunities for students (mobility flows within courses, semester exchange, summer schools, use of international case studies, literature from overseas, provision of double and joint degrees), international recruitment, accreditations, and internationalisation of the faculty. Modern Languages staff took this further, demonstrating a deep engagement with the potential of an internationalised curriculum to provide a positive and fully transformative student experience. Rather than just the things students might do, they understand IOC as fostering "the ability [of students] to think, to perceive things through the medium of [language studied]". They reflect that it is also important to ensure the teaching approach is "culturally driven" to make students think, observe, and respond as international individuals - to be "a rounded thinker and citizen of that branch of the world in that language". The difference between having international components within curricula and changing the mind set of students was also echoed by one science undergraduate course leader: "we have the content of the modules which is about awareness raising and students investigate global issues and they're clearly developing internationalisation skills doing that.....but it's a different type of internationalisation than actually experiencing a different culture". This understanding of IOC, however, is not reflected in the documentation of these science courses. This disconnect is also observed in Construction, but here staff recognise and include particular kinds of activities associated with IOC (mainly around student mobility), but comments indicate that they do not always connect these to the deeper transformational effects possible through such international and intercultural engagement. This is illustrative of a lack of staff understanding of what global citizenship means as discussed below.

\section{Global citizenship as a graduate attribute}

Global citizenship is a complex, changeable, and contested concept (Hunter et al. 2006). The contemporary drive within HEIs to embrace internationalisation has seen its appearance in a different and new context to that of the philosophical debates regarding citizenship, globalisation, and the nature and possibilities of world or global governance (Carter 2001). In this more recent context, it has been linked with or presented as a set of competencies and located within institutional plans as a graduate attribute-something desirable, that university leaders wish to see developed throughout the curriculum for students to acquire regardless of subject or disciplinary background, and NTU is no exception. Whilst the articulation of global citizenship in this way varies across the HEI sector, the competencies that are often ascribed to it include an openness to or awareness of others, an appreciation of social and cultural diversity, a respect for human rights, and a sense of public or civic responsibility. When used as a graduate attribute, however, its meaning is often assumed and not specified by institutions (for an exception, see Jones and Killick 2013) and, as found in the semi-structured interviews reported on here, academic staff are often not clear on how such a graduate attribute might best be embedded into their courses and teaching. This can lead to a form-filling approach where academics follow the guidelines regarding graduate attributes "without considering how they are actually going to develop and test these attributes" (Leask 2013: 10). This is evident, as indicated above, where analysis of documentation showed disconnect between institutional direction and local understanding/implementation of global citizenship as a graduate attribute.

In some subject areas, interviews indicated a clear, shared understanding of what makes a global citizen. For instance, undergraduate and postgraduate Course Leaders of 
International Relations courses, as may be expected, were clear that it involves "awareness of your place in the world and your similarities and differences to other people in their positions in the world as well". Childhood Studies staff demonstrated an equally strong understanding of this attribute, extending the concept to focus on how a cultural transition aids understanding when working with children in the multicultural UK setting. As a course leader suggested, “... it helps them [students] understand where those children have come from, about their cultural values and beliefs and all of the things associated with that". This is tied to a staff understanding of where their graduates may be employed, working with children from diverse cultural backgrounds. There is an evident lack of confidence in full understanding in other disciplines, encompassing some in which opportunities for development of this attribute are taken. When asked what global citizenship meant to them, a Psychology Course Leader responded, “...I wouldn't say I know $100 \%$ what exactly that concept means"; and the Computing International Champion replied: "It's obviously more important to the humanities, I guess, than with science".

In other disciplines, there was a much deeper and active contestation of the use of the term as a graduate attribute by the university. Clifford and Montgomery (2014) recognise that the "good feel" of the concept is attractive, but as Henderson (2013) suggests there is a danger of institutions relying on "empty rhetoric" (p. 736). As a case in point, colleagues in Media expressed a desire for more critical thinking on what global citizenship means: "...a lot of the course is spent thinking critically about what we might mean by globalisation in terms of the relationship between culture, politics and the economy, then announcing that we've produced a global citizen strikes me as being - as opening up all sorts of questions. What kind of global citizen?" The staff in this area are clearly sceptical about the use of global citizenship as a graduate attribute if understood solely in terms of employability, whereby the capacity for continued critical reflection, which engagement with multiple and diverse communities demands, is subordinated to market demands and opportunities for greater economic selfadvancement.

Joseph (2013) suggests that in contrast to the "economic rationalist" model, a more transformative approach can be identified, one in which higher education is focused on developing skills to encourage individuals to seek to challenge assumed cultural hierarchies (see also Leask and Bridge 2013). Such an approach gives greater emphasis to the cultural and social aspects of global citizenship and the potential impact of intercultural learning upon the curriculum. This is a more expansive and critical understanding of global citizenship - one that enables students to "challenge familiar and typical practices, norms, values and beliefs" (Caruana 2011), question Western bias and privilege within learning and teaching, and potentially significantly revise current teaching practice. It is this quality of debate that is reflected by colleagues from Media, indicating deep and meaningful engagement, and realisation that this is a complicated concept, which possibly requires further unpacking. While desirable to do this, it is integral to Media and Cultural Studies as disciplines, compared with Computing, where there is little sense of the cultural dependency of the taught curriculum and, instead, a sense that "the curriculum for computing is obviously universal [because] most countries use the same software, same packages".

In addition to these concerns and confusions around what global citizenship might be understood to mean, staff were also mindful that the idea of citizenship required transformation and action on the part of students, and that there is sometimes resistance to this. For example, in Fashion, while there is active international mobility, it is still difficult to 
convince students of the need to be global citizens. Fashion courses typically attract middle-class female students, and one course leader responded: "I think it is difficult. I think there's undoubtedly a Northern European snobbery, where they feel that they are uniquely placed globally to have to try less hard. ...... It's quite tough to get them to have some sense that the world isn't driven by a UK perspective." In addition, the international champion in Law reported that: "...I don't think the English students would regard them[selves] as global citizens. I don't [think] that would even enter their mind to be honest." "I don't think you would directly challenge that. I think what we would do is say that there are obviously examples of good practice elsewhere. We wouldn't challenge their national identity." "...we do a comparative view". The undergraduate Course Leader in Construction said about global citizenship: “.... is that just like an awareness that they are a citizen of the globe? ... will they be global citizens? Well they've gone to Europe for a week and they've learnt about international property industry, they've met some international students while they're here. Maybe not-if not on the course then I'm sure in Nottingham somewhere. So if that makes them a global citizen, that's fine. But you're almost suggesting somehow-hidden behind that, you could argue that maybe there's some kind of political driver that somehow people lose the shackles of their own citizenship if you like and see themselves as a citizen of the world". Such comments reflect earlier findings (Breit et al. 2013), that students bring different understandings to the table, which can be quite entrenched, as they are from "different social, educational, and cultural settings...[with] diverse learning experiences and traditions" (p. 120). This study highlights that academics need to be wary of having an "imagined or archetypal student" in mind (p. 121). It is important to consider "how students see themselves and how this understanding shapes their thinking, actions and learning" (p. 132) within their specific disciplinary setting when introducing concepts like global citizenship.

Where subject matter required the deepest engagement with the international, staff perceptions of students' attitudes were more positive, e.g., a staff member from International Relations stated: "I think that our students do leave thinking of themselves as global citizens because that's what they've had for the past three years; they've been challenged to put themselves into those spaces intellectually and think about things like from global ethics down to global political economy. They are encouraged to think through at that geographical or geopolitical level. So yes I would be quite confident that they think of themselves like that".

\section{Balancing local implementation with institutional strategy}

There are a number of reasons for the challenges and observed disconnections between strategy and practice, which include disciplinary differences, individual academics, and active debate and contestation of key terms. What is clear, however, is that with the exception of some subject areas, such as International Relations, where the links between internationalisation and the curriculum are obvious, or disciplines such as Childhood Studies, where future work contexts determine that the skills IOC promises to deliver are relevant, there was very little local ownership of the IOC agenda and little evidence of the practices associated with IOC emerging organically from within academic teams. Developing such local ownership, therefore, would appear to be a clear area where effort should be focused.

It is some time since De Vita and Case (2003) highlighted that internationalisation was being dominated by financial and market-force considerations, rather than by the fundamentals 
of educational processes to ensure staff and student engagement with multicultural teaching and learning. As indicated in the research reported here, this tension is still alive in the minds of many academic staff, and is something which may be encouraged by a very top-down management-led directive approach to changing the curriculum (Florenthal and TolstikovMast 2012). The results of studies presented here reflect some of the problems of a top-down approach to IOC. Comments from undergraduate course leaders across the University included "the top can look at things a little bit too top down and we do end up with one size fits all solutions". There is also evidence that top-down intentions are not always effectively filtered down to course teams. For example, while there are guidelines, some course members clearly remain unaware: "If we had guidance when courses are being written, rewritten, revalidated, assessed each year, that there was an element of internationalisation that had to be adapted or at least thought about, that would be incredibly useful. That would change things a great deal." In line with the findings of previous research, some comments reflected the desire for "the wide experience within the Schools to be listened to carefully" in decision-making from an early stage, particularly to encourage discipline-specific input.

There are no simple answers to these types of issues, particularly in large, diverse, and complex institutions, such as universities. What this project confirms, however, is that staff engagement is key to effective and sustained IOC (Stohl 2007) and that strategies must enable staff within subjects to provide the appropriate contextualisation (Agnew 2012).

Ljosland (2015) suggests that successful combination of bottom-up and top-down approaches are most effective. Using the Norwegian HE sector, and the top-down directive that teaching was to be done in English, Ljosland highlighted the reluctance of some staff to engage for fear of losing their own language and cultural identity. By balancing this expressed concern with the views of other key teaching staff, and ensuring a proper understanding of the rationale behind the decision, with reassurance that cultural identity would be preserved, staff became engaged for a successful outcome. The authors suggest that, to avoid staff feeling disempowered and undervalued professionally, clear strategies are implemented to bridge top-down impositions with bottom-up initiatives. Barnett's (1994) framework for understanding how quality evaluation processes are effectively embedded in institutions forms a useful heuristic device for thinking through the relationships between organisational approach to change, staff engagement, and strategic effectiveness.

As can be seen from Fig. 1, bureaucratic control/power runs counter to epistemic authority ("collegial power"), and this can mean that where there is limited dialogue, decisions are imposed, and although the outcomes might be reliable for quality assurance purposes, they may have low validity for staff. Diametrically opposed to this, collegial control can engage self-responsibility, self-evaluation, acknowledgment of the disciplinary context, and allow an equal voice for contributors. The outcomes - in Barnett's case, full compliance with quality standards - may have lower reliability, but will have enhanced validity at faculty level. Running across this control axis are the ways in which the power is enacted and the impact on contributors ("enlightenment") - emancipatory activities enable groups to conduct processes for themselves, to be self-transformative and have internal accountability and empowerment, whereas a technicist approach requires imposed processes, effectively requiring little input from academic staff involved. In line with Barnett's more generalised findings concerning quality evaluation, overall activities that are perceived to be collegial and emancipatory have the potential for best staff engagement. It is possible to use a modification of Barnett's model to demonstrate the relative positioning of approaches to/features of IOC, as illustrated below (Fig. 2). This shows the position of a variety of aspects of internationalisation 


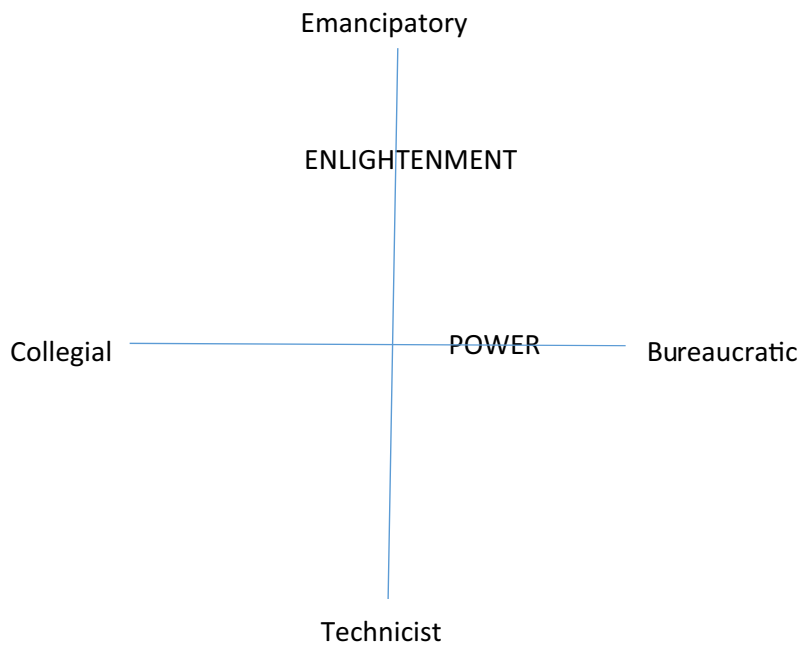

Fig. 1 Process control-from Barnett (1994)

as determined through the current investigation, and allows more desirable locations to be suggested for activities on the axes, and means of achieving them.

\section{Emancipatory}

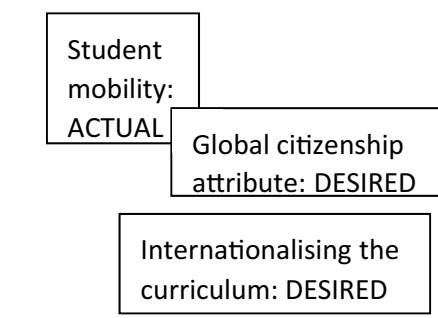

Collegial

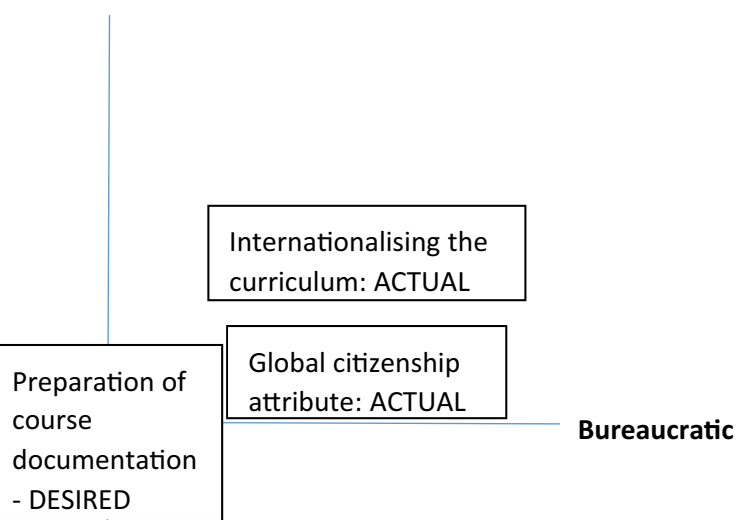

Preparation of
course
documentation -
ACTUAL

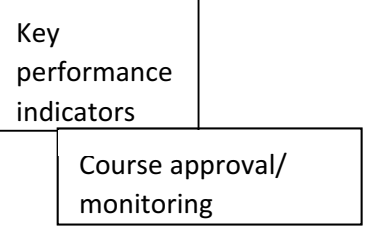

Technicist

Fig. 2 Mapping of IOC activities to Barnett (1994)'s axes of quality evaluation. ACTUAL indicates the current positioning of items on the axes. DESIRED indicates the position the authors suggest items should move towards. Items without ACTUAL/DESIRED tags are at the appropriate place on the axes 


\section{Activities requiring greatest movement on the axes}

It is clear that at the time of this research, the notion of global citizenship sat in an unfavourable place on these axes. While there was a relatively rich and complex articulation of this attribute in the Strategy, the lack of institutional effort to assist all staff in interpreting how this might be reflected in different disciplinary contexts created a polarisation amongst academic teams. While the lack of clear guidance created space for potential emancipatory enactment in subject areas with overt global content, it placed staff from other disciplines in an uncomfortable position, as illustrated above. For those staff less familiar with global citizenship, they perceived it to be a concept of bureaucratic origin poorly linked to their local disciplinary contexts. The response of those who felt alienated from the terminology was to resort to a surface level engagement, the net effect being a lack of opportunity for students and a poor articulation of what was happening in documentation (Bartell 2003). To overcome this for all staff, global citizenship needs to move towards the left-hand quadrant in Fig. 2, whereby ownership is transferred to the academy. To enable this, the current investigation suggests there is need for initiatives both locally and institutionally to agree upon clear definitions in conjunction with staff, and provision of examples to facilitate contextualisation.

\section{Activities needing some movement on the axes}

To move to a more complete and student-friendly set of documentation requires a more emancipatory staff interaction with the process (i.e., a vertical shift in Fig. 2), such that full justice is done to the richness of what is offered in the curriculum-describing the course rather than "ticking boxes". For example, Physics documentation is extremely light on opportunities for internationalisation, and yet staff regularly take students on overseas field trips, and discuss the global impact of aspects such as nuclear physics. How this will work in practice needs consideration - time is required for staff to reflect on and articulate the best activities and approaches for their specialism. To enable this, the ownership of IOC and what it means needs to move horizontally, to enable local ownership and enactment, once full definitions have been discussed and agreed upon institutionally. A good example of this in action has been described by Breit et al. (2013). Using Journalism as the subject area under investigation in an Australian institution, the authors recognised that although clearly seated in an international arena, the subject tended to be taught around western principles. They highlight the tendency to assume that what they view from a privileged position is globally correct, but that this overlooks the local context. They engaged a group of staff in thinking this through and the true meaning of IOC in their context, fully engaging with them and setting up a shared understanding. By negotiation and discussion, this group agreed that in their journalistic context, this referred to de-Westernisation of the curriculum, specifically "developing awareness of the diversity of approaches and understandings of journalism as well as helping students to understand how their understanding of journalism affects what they do and how they feel" (p. 131). With this shared understanding, they were then able to move forward with re-specifying their curriculum.

\section{Activities which should not move on the axes}

Course approval and monitoring are, and should remain, in the lower right-hand quadrant. By their very nature, they are top-down bureaucratic processes that require compliance with 
regulatory structures. As part of approval, documentation should be produced and this should be the vehicle through which activities involved in IOC are articulated to all stakeholders. It cannot be forgotten, however, that evaluation of delivery, effectiveness, and impact is also important in terms of encouraging reflection and improvement. Monitoring and approval of courses will remain in the bottom-right quadrant to ensure balance and appropriate oversight (Fig. 2-including monitoring of key performance indicators). This is clearly needed, as illustrated by findings reported in this paper - even with a clear articulation of requirement for particular aspects to be included in course documentation, the extent of this has been variable as illustrated in Table 1. While this "form-filling" may be seen as an exercise in bureaucratic power, it is also a key communication device between staff and students, and is hence vital.

Perhaps the most successful aspect of IOC to date has been student mobility. This has grown in a collegiate and emancipatory way across the University, and opportunities exist across all courses (Table 1 and Fig. 2). There is a degree of bureaucratic control over the processes involved, but this is an example of an initiative which has evolved from staff interests and become embedded, albeit with the caveats discussed above regarding lack of full exploitation across all disciplines of the potential of this important activity for enabling development of global citizenship attributes. It is this latter area which requires further development.

Sustainability of IOC requires a cultural shift and reduced over-reliance on one or two "champions" (enthusiasts fully bought into the concept and active in its local interpretation and enactment) in each area. The desire (illustrated in Fig. 2) to move understanding and enactment of global citizenship and IOC towards the top-left quadrant will therefore involve significant planning and support for staff. There is a clear role for individuals to be charged to act as intermediates between those setting strategy (top-down) and those charged with implementation, allowing a significant bottom-up influence and full subject-level ownership of implementation. This is in line with Hudzik and McCarthy (2012). In their report on leading comprehensive internationalisation, they suggest the use of a flexible leadership framework (at all levels) regarding the what, why, and how of strategy and action. By having a clear message, clear communication channels and flexible leadership structure to enable contextualisation, coupled with clear reward structures, sustainable implementation is possible. This is in line with Knight (1994)'s view that a more "decentralised implementation involves the largest number of people, and so builds energy, commitment, and creativity at the individual and faculty level" (p. 9).

Decentralisation/flexible leadership would "soften" the axes in Fig. 1-potentially shortening the Bureaucratic and Technicist axes and more fully engaging faculty, and is in line with achievement of NTU's goals.

\section{Conclusion}

International opportunities were apparent across all 15 subject disciplines surveyed in NTU, although the depth of engagement of both staff and students varied depending on subject area, and was influenced by the extent of understanding and ownership of the concepts by faculty. Certain disciplines are inherently receptive to the idea of internationalisation, such as Media, International Relations, Modern Languages, and staff fully engage with debate and inference of this in their context and more widely. This is not, however, the case across all disciplines, 
many of which have effectively had internationalisation imposed on them as a strategic objective, and the accompanying graduate skill of global citizenship to provide, without contextualising debate and agreement. Previous research and aspects from the current study clearly indicate that local understanding and ownership of initiatives is potentially most effective for full engagement. To encourage this, Barnett (1994)'s axes are useful as a way of accounting for current practice, and identifying areas for action where there would be a clear wish to move the centre of ownership and power towards the academy (Fig. 2). This is not to decry or remove institutional oversight in respect of quality assurance and monitoring of key performance indicators. It is clear that the most successful aspect of IOC - student mobilityhas been successful due to its local subject level ownership, although as discussed above, full exploitation of the potential of this activity has not been made in all cases.

It is important to consider the starting point and background of staff as they enter the sphere of IOC, and to provide appropriate training, motivation, and facilitation (Leask 2015) for them to engage successfully, and to empower them to take ownership. The point about staff background is important - a previous study in America showed that staff are most likely to disagree that internationalising the curriculum played a part in their professional beliefs and practices were male, scientists, spoke one or two languages (including their own), and had never lived outside North America (Drake 2013). Recognising such predispositions and challenging them will therefore be important in the design of staff development activities to encourage engagement, including opportunities for staff mobility, and these will potentially be more polarised across disciplinary divides.

Where local ownership of IOC has not been taken, misconceptions around it and its intended graduate attribute outcomes are evident-for example in subject areas such as science, where discussion around what makes a global (scientific) citizen has not taken place amongst the academy in any meaningful way.

Even when discussed, concepts such as global citizenship and global competence are difficult to articulate within course learning outcomes (Jones and Killick 2013; Leask 2001). This requires concerted action at institutional and local levels to agree upon definitions and provide exemplars so all staff become engaged and can contextualise to their own discipline the overall strategic vision. Successful internationalisation in higher education relies on engaged, enthusiastic staff who have the knowledge, tools, headspace, and authority to act as best fits their subject disciplines (Dewey and Duff 2009; Leask and Beelen 2009; Friesen 2012), and effective use of the resources that institutions have in their international staff and students (Sawir 2013). This needs to be fully embedded in routine operation to be sustainable, but not overly prescriptive in nature such that it stifles innovation (Ilieva et al. 2014).

In conclusion, it is suggested to move to a fully internationalised curriculum:

- University management must recognise the different requirements of individuals and subject disciplines in respect of implementing top-down initiatives, and the need for subject-level ownership and empowerment.

- Concerted staff development is implemented to enable local contextualised discussion of what IOC and global citizenship mean to each individual and within each discipline, with input from key strategic personnel to ensure alignment with university strategy.

- Ownership of IOC is clearly located at the discipline level, with appropriate institutional support to ensure clear articulation of philosophies, opportunities, and intended outcomes for students; 
- Appropriate understanding and implementation are checked through standard course quality assurance processes.

Acknowledgements We gratefully acknowledge the HEA and Santander for providing funding in support of this research, and the work of Noemhi Dehling and Adam Spencer in reviewing documentation and carrying out interviews.

Open Access This article is distributed under the terms of the Creative Commons Attribution 4.0 International License (http://creativecommons.org/licenses/by/4.0/), which permits unrestricted use, distribution, and reproduction in any medium, provided you give appropriate credit to the original author(s) and the source, provide a link to the Creative Commons license, and indicate if changes were made.

\section{References}

Agnew, M. (2012). Strategic planning: an examination of the role of disciplines in sustaining internationalisation of the university. Journal of Studies in International Education, 17(2), 183-202.

Barnett, R. (1994). Power, enlightenment and quality evaluation. European Journal of Education, 29(2), 165179.

Bartell, M. (2003). Internationalisation of universities: a university culture-based framework. Higher Education, $45,43-70$.

Bell, M. (2004). Internationalising the higher education curriculum — do academics agree? Case Study write-up. Australia: University of Wollongong.

Bond, S.L., Qian, J., \& Huang, J. (2003). The role of faculty in internationalising the undergraduate curriculum and classroom experience. Can. Bureau for Int. Educ. Research, Millenium Series no. 8.

Breit, R., Obijiofor, L., \& Fitzgerald, R. (2013). Internationalization as de-westernization of the curriculum: the case of journalism at an Australian University. Journal of Studies in International Education, 17(2), 119135.

Carter, A. (2001). The political theory of global citizenship. Taylor \& Francis. Retrieved 21 March 2017, from $<$ http://www.myilibrary.com?ID=32633>

Caruana, V. (2011). The challenge of global citizenship education in the 21 st century university: a case for service learning and community volunteering? In V. Clifford \& C. Montgomery (Eds.), Moving towards internationalisation of the curriculum for global citizenship in higher education (pp. 227-250). Oxford: Oxford Centre for Staff and Learning Development.

Clifford, V. (2009). Engaging the disciplines in internationalising the curriculum. International Journal of Academic Development, 14, 133-143.

Clifford, V. A. (2011). Internationalising the home student. Higher Education Research and Development, 30(5), 555-557.

Clifford, V., \& Montgomery, C. (2014). Challenging conceptions of Western higher education and promoting graduates as global citizens. Higher Education Quarterly, 68, 28-45.

Clifford, V., \& Montgomery, C. (2015). Transformative learning through internationalisation of the curriculum in higher education. Journal of Transformative Education, 13(1), 46-64.

Crowther, P., Joris, M., Otten, M., Nilsson, B., Teekens, H., \& Wachter, B. (2000). Internationalisation at home: a position paper. Amsterdam: EAIE.

De Vita, G., \& Case, P. (2003). Rethinking the internationalising agenda in UK higher education. Journal of Further and Higher Education, 27(4), 383-398.

Dewey, P., \& Duff, S. (2009). Reason before passion: faculty views on internationalisation in higher education. Higher Education, 58, 491-504.

Drake, H. (2013). Learning from peers: the role of the student advisor in internationalising the European Studies curriculum. Baltimore: EUSA Conference Paper.

Egron-Polak, E., \& Hudson, R. (2014). Internationalization of higher education: growing expectations, fundamental values - IAU 4th Global Survey, International Association of Universities.

Florenthal, B., \& Tolstikov-Mast, Y. (2012). Organizational culture: comparing faculty and staff perspectives. Journal of Higher Education Theory and Practice, 12(6), 81-90.

Friesen, R. (2012). Faculty member engagement in Canadian University internationalisation: a consideration of understanding, motivation and rationales. Journal of Studies in International Education, 17(3), $209-227$. 
Green, W., \& Whitsed, C. (2012). Reflections on an alternative approach to continuing professional learning for internationalization of the curriculum across disciplines. Journal of Studies in International Education, 20(10), 1-17.

Harrison, N. (2015). Practice, problems and power in internationalisation at home: critical reflections on recent research evidence. Teaching in Higher Education, 20(4), 412-430.

Hayden, M. (2013). A review of curriculum in the UK: internationalising in a changing context. The Curriculum Journal, 24(1), 8-26.

Henderson, J. (2013). Strategies for critiquing global citizenry: undergraduate research as a possible vehicle. Teaching in Higher Education, 18(7), 736-747.

Hudzik, J.K., \& McCarthy, J.S. (2012). Leading comprehensive internationalization: strategy and tactics for action. NAFSA: Association of International Educators.

Hunter, B., White, G. P., \& Godbey, G. C. (2006). What does it mean to be globally competent? Journal of Studies in International Education, 10(3), 267-285.

Ilieva, R., Beck, K., \& Waterstone, B. (2014). Towards sustainable internationalisation of higher education. Higher Education, 68, 875-889.

Jones, E., \& Killick, D. (2013). Graduate attributes and the internationalized curriculum: embedding a global outlook in disciplinary learning outcomes. Journal of Studies in International Education, 17(2), 165-182.

Joseph, C. (2013). Internationalising the curriculum: economic rationalist or transformative approach. 41(1), ASA footnotes. Retrieved 24 March 2017, http://www.asanet.org/sites/default/files/fn_2013_01.pdf.

Knight, J. (1994). Internationalization: elements and checkpoints (Vol. 7). Canadian Bureau for International Education Research.

Leask, B. (2013). Internationalizing the curriculum in the disciplines_imagining new possibilities. Journal of Studies in International Education, 17(2), 103-118.

Leask, B. (2015) Internationalizing the Curriculum", Internationalization in Higher Education Series, Routledge, UK and NY.

Leask, B., \& Beelen J. (2009). Engaging academic staff in international education in Europe and Australia. Paper from IEAA-EAIE Symposium: Advancing Australia-Europe Engagement. Background paper 2.

Leask, B., \& Bridge, C. (2013). Comparing internationalisation of the curriculum in action across disciplines: theoretical and practical perspectives. Compare, 43(1), 79-101.

Ljosland, R. (2015). Policymaking as a multi-layered activity. A case study from the higher education sector in Norway. Higher Education, 70, 611-627.

Newstead, C., Gann, R., Kirk, S., \& Rounsaville, C. (2015). Disciplinary perspectives on internationalising the curriculum. A report for the HEA, UK.

Sanderson, G. (2011). Internationalisation and teaching in higher education. Higher Education Research and Development, 30(5), 661-676.

Sawir, E. (2011). Academic staff response to international students and internationalising the curriculum: the impact of disciplinary differences. International Journal for Academic Development, 16(1), 45-57.

Sawir, E. (2013). Internationalisation of higher education curriculum: the contribution of international students. Globalisation, Societies and Education, 11(3), 359-378.

Stohl, M. (2007). We have met the enemy and he is us: the role of the faculty in the internationalization of higher education in the coming decade. Journal of Studies in International Education, 11(3-4), 359-372.

Van der Wende, M. (1997). Internationalising the curriculum in Dutch higher education: an international perspective. Journal of International Studies in Education, Fall, 1997, 53-72. 